\title{
Cx43 in Neural Progenitors Promotes Glioma Invasion in a 3D Culture System
}

\author{
Kanika Khosla, Christian C. Naus and Wun Chey Sin * \\ Department of Cellular and Physiological Sciences, Life Sciences Institute, The University of British Columbia, \\ Vancouver, BC V6T 1Z3, Canada; kanika2856@hotmail.com (K.K.); ccnaus@gmail.com (C.C.N.) \\ * Correspondence: wcsin@mail.ubc.ca
}

Received: 26 June 2020; Accepted: 20 July 2020; Published: 23 July 2020

\begin{abstract}
The environment that envelops the cancer cells intimately affects the malignancy of human cancers. In the case of glioma, an aggressive adult brain cancer, its high rate of recurrence after total resection is responsible for a poor prognosis. Connexin $43(\mathrm{Cx} 43)$ is a gap junction protein with a prominent presence in glioma-associated normal brain cells, specifically in the reactive astrocytes. We previously demonstrated that elimination of $\mathrm{C} \times 43$ in these astrocytes reduces glioma invasion in a syngeneic mouse model. To further our investigation in human glioma cells, we developed a scaffold-free 3D platform that takes into account both the tumor and its interaction with the surrounding tissue. Using cell-tracking dyes and 3D laser scanning confocal microscopy, we now report that the elimination of $\mathrm{Cx} 43$ protein in neural progenitor spheroids reduced the invasiveness of human brain tumor-initiating cells, confirming our earlier observation in an intact mouse brain. By investigating the glioma invasion in a defined multicellular system with a tumor boundary that mimics the intact brain environment, our findings strengthen $\mathrm{Cx} 43$ as a candidate target for glioma control.
\end{abstract}

Keywords: Cx43; glioma; invasion; 3D; time-lapse imaging; human brain tumor-initiating cells

\section{Introduction}

Cancer research has mostly focused on understanding and reversing the deleterious effect due to aberrant expression of mutated proteins in tumor cells. In this aspect, the gene of the ubiquitously expressed Cx43 (Gja1) is not usually altered in human cancers, based on a finding from a large cancer genome atlas (TCGA: https://www.cancer.gov/tcga). However, a TCGA query revealed preferential upregulation of Cx43 in malignant glioma [1], the most common brain cancer in adults, with very poor prognosis due to the high chance of recurrence, even after a successful total resection [2]. A report by Cottin and colleagues further determined that more than $10 \%$ of human gliomas displayed strong Cx43 immunostaining [3]. Although earlier work showed that the downregulation or absence of Cx43-mediated intercellular communication is associated with increased malignancy in tumor cells [4,5], it is now clear that Cx43 overexpression in tumor cells promotes invasion [4,6,7], especially in the presence of normal stromal cells such as astrocytes [8-11]. Indeed, there is strong evidence to suggest that $\mathrm{Cx} 43$ has a pivotal role in cancer of the central nervous system [12] and a promising therapeutic target for gliomas [13].

The microenvironment of cancer cells has gained prominence in driving tumor invasion [14]. Since one of the major functions of a gap junction is to mediate intercellular communication, Cx43 is well positioned to participate in microenvironment signaling. Cx43 protein levels are significantly enhanced in glioma-associated astrocytes, especially at the region adjacent to the tumor core and is crucial to the spreading of glioma cells at the invasive niche [15]. These findings suggest that Cx43 may modulate invasion via glioma-astrocyte communication. Indeed, in vivo studies with rats have found 
that glioma cells can increase their invasion by forming gap junctional intercellular communication (GJIC) with astrocytes [10,11]. Co-culture of U87MG human glioma cells with human astrocytes also enhances the invasive behavior of the glioma cells in a GJIC-dependent manner [16].

We previously demonstrated that elimination of $\mathrm{Cx} 43$ in astrocytes reduced glioma invasion in a syngeneic intracranial mouse model [15]. To extend this investigation on human patient glioma stem cells, we developed a scaffold-free 3D tissue culture model system [17] to examine the invasion of glioma cells into mouse progenitor cells cultured as spheroids and followed the invasion of human glioma cells in real time using cell-tracking dyes and confocal microscopy. We showed that human glioma cells exhibited reduced invasion into mouse spheroids when $\mathrm{Cx} 43$ protein was removed from the mouse progenitors. Our results from the 3D culture model confirmed our earlier observation in an intact mouse brain, strengthening the role of $\mathrm{Cx} 43$ in enhancing glioma invasion by being a conduit for the tumor cells to interact with the stromal environment.

\section{Results}

\subsection{The Invasiveness of Human BTICs in 3D Culture Mirrored its Pathogenicity}

Cancer stem cells are key drivers of tumor progression and invasion [18,19]. Therefore, we first characterized 2 lines of human brain tumor-initiating cells (BTICs), GBM4 and GBM8, which have been propagated as spheroids in serum-free medium [20]. GBM4 is less invasive of the two lines, with nodular pathology and massive endothelial proliferation [20]. In contrast, GBM8 is very invasive, with a PNET-like pathology [20]. Multiple Cx43 protein bands that corresponded to different phosphorylated isoforms [21,22] were detected in the cell lysates of both BTICs (Figure 1b). The smallest Cx43 band detected in GBM4 was absent in GBM8 but present in GL261, a mouse glioma cell line that was used in our intracranial mouse glioma model [15]. Taken together, the results indicated that these BTICs have the potential to form Cx43 channels with each other and with adjacent normal cells.

We examined their invasiveness in a 3D human glioma model [17] by measuring the migration distance of GBM4 (red) and GBM8 (green) in wild-type (WT) mouse progenitor (blue) spheroids Figure 1a, Figure 2a). After $2 \mathrm{~h}$ of co-culture, isolated single GBM8 cells (white arrowhead) were detected in the mouse spheroids (Figure 2b). In contrast, GBM4 preferentially invaded mouse spheroids in a collective manner (white arrow) while maintaining contact with neighboring cells (Figure $2 b$ ). Indeed, GBM8 cells exhibited higher velocity $(2.657 \mu \mathrm{m} / \mathrm{min}+/-0.212, n=195)$ than GBM4 cells $(1.928 \mu \mathrm{m} / \mathrm{min}+/-0.150, n=171)$ in WT spheroids (Figure 2c). Taken together, our results from the 3D spheroid invasion platform are in agreement with their invasiveness in a human patient.

\subsection{The Absence of Cx43 in Mouse Progenitor Cells Reduces Glioma Invasion}

In order to validate our 3D invasion model platform, we made use of mouse WT and Cx43 knockout $(\mathrm{KO})$ cells from our earlier study showing that elimination of $\mathrm{Cx} 43$ in astrocytes reduces glioma invasion in an intact mouse model [15]. We first examined the characteristics of mouse WT and Cx43 KO spheroids with antibodies against glial fibrillary acidic protein (GFAP) and Cx43, both of which are highly expressed in reactive astrocytes induced by a brain lesion [23]. GFAP was detected in both WT and KO spheroids (Figure 3a), which is in agreement with our previous observation that abolition of Cx43 in astrocytes in vivo does not affect GFAP expression $[15,23]$. In contrast, the punctate staining of $\mathrm{Cx} 43$ was only detected in WT but not the KO spheroids (Figure 3a), confirming successful knockout of $\mathrm{Cx} 43$ in the mouse progenitor cells. We decided to examine only GBM8 co-cultured with WT and KO spheroids in this series of experiments due to its increased invasiveness compared to GBM4 (Figure 2). After co-culture for $2 \mathrm{~h}$, there were more GBM8 cells in the WT mouse spheroids than in KO spheroids (Figure 3b). When we measured the velocity of GBM8 cells that had invaded into the WT spheroid after exiting from the BTICs spheroid, we found that GBM8 moved significantly slower in $\mathrm{KO}(1.083 \mu \mathrm{m} / \mathrm{min}+/-0.205, n=102)$ than in WT $(3.495 \mu \mathrm{m} / \mathrm{min}+/-0.483, n=102)$ spheroids (Figure 3c). Therefore, as demonstrated previously in the intracranial mouse glioma model [15], 
the absence of $\mathrm{Cx} 43$ in normal cells affects the invasiveness of tumor cells, strengthening a critical role of $\mathrm{Cx} 43$ in the microenvironment.

a

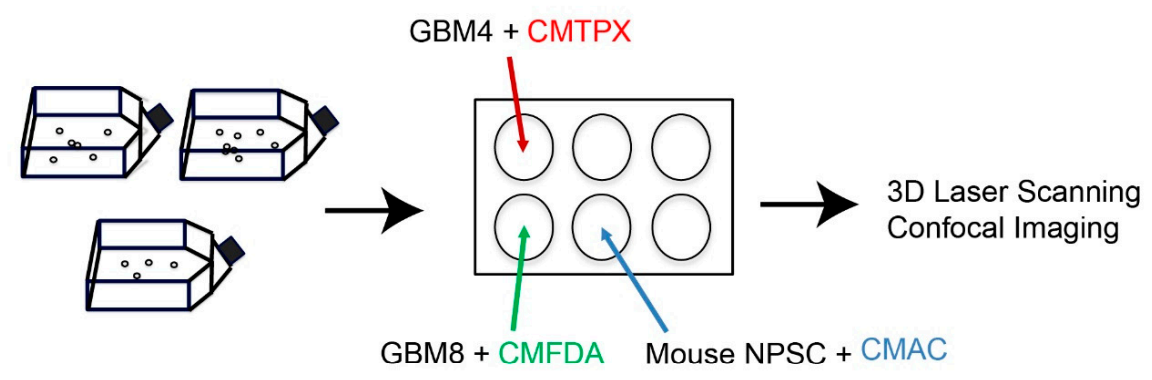

b

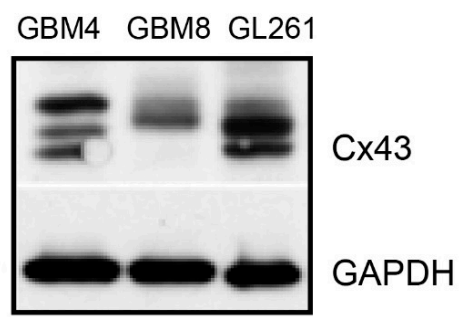

Figure 1. Cx43 protein is expressed in human brain tumor-initiating cells GBM4 and GBM8. (a) Schematic diagram illustrating the culture and labeling of spheroids with cell-tracker dyes (CMTPX, CMFDA and CMAC) to distinguish them for live imaging by confocal microscopy. (b) Western analysis of cell lysates of GBM4 and GBM8 with anti-Cx43 antibody showing multiple protein bands corresponding to different phosphorylated isoforms. Cx43 species in mouse GL261 glioma cells used in our intracranial mouse implantation [15] was included as a comparison. GAPDH was used as loading control.

a
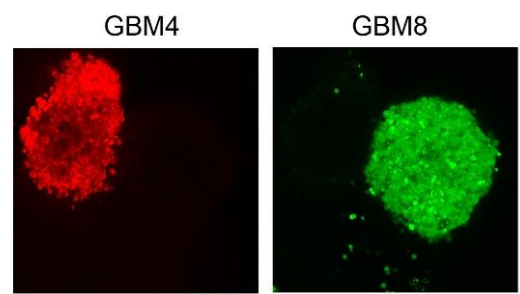

Mouse cells
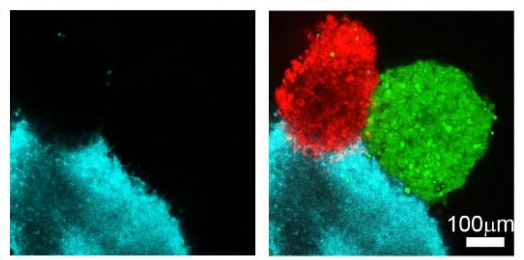

b

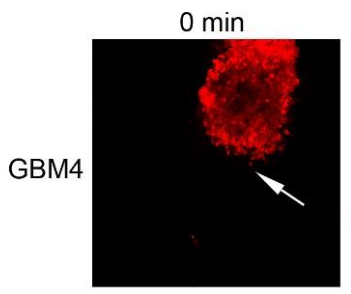

$30 \mathrm{~min}$

$60 \min$
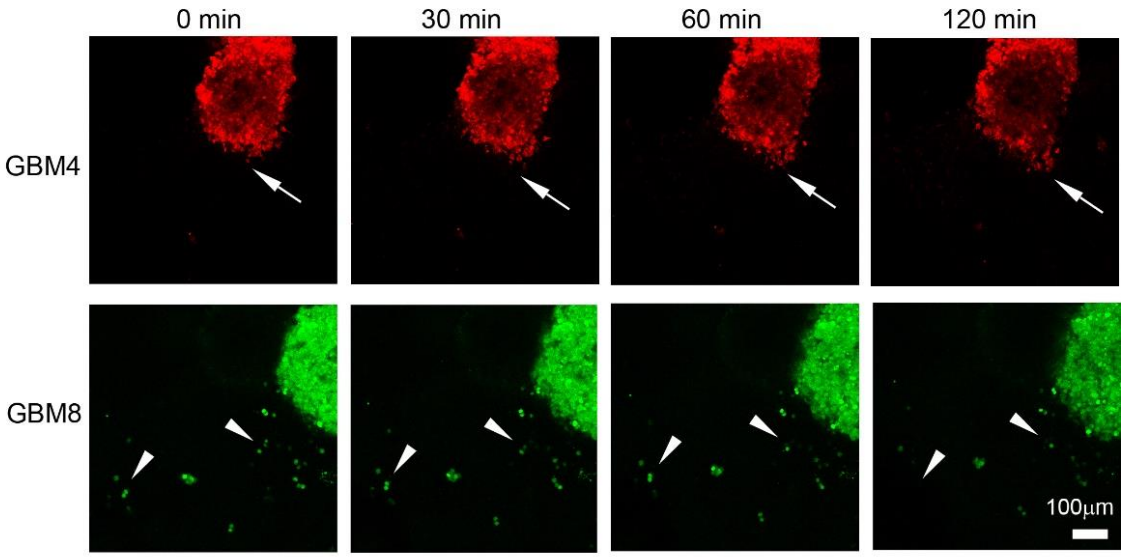

Figure 2. Cont. 

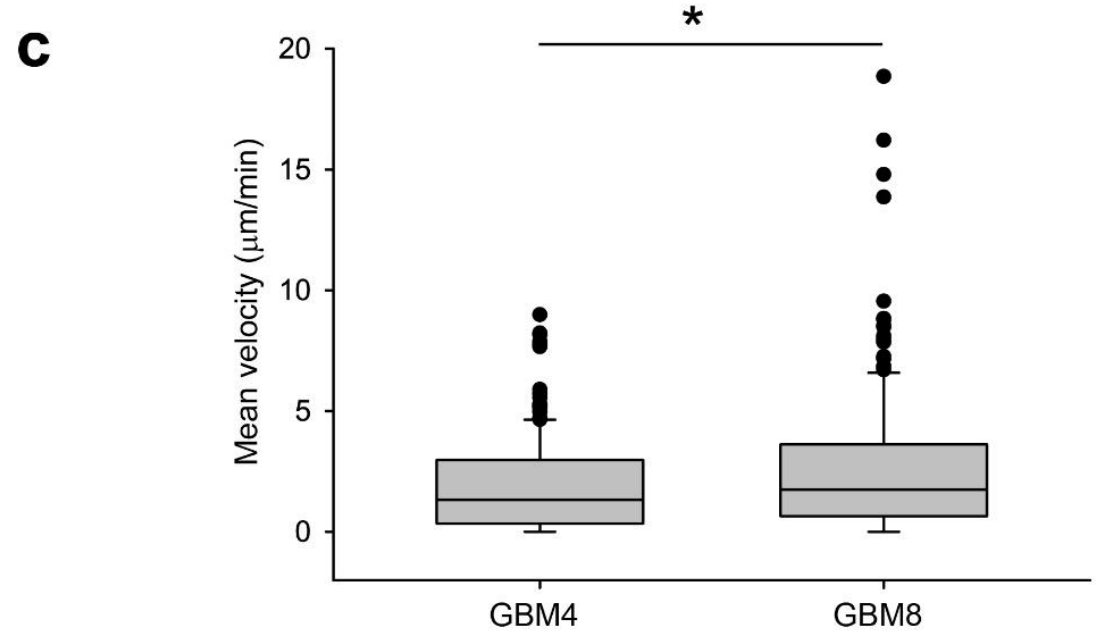

Figure 2. Invasiveness of GBM4 and GBM8 correlate with their pathogenicity in human patients. (a) Co-culture of GBM4 (red), GBM8 (green) and C57BL6 mouse neural progenitor cell derived spheroids (blue) in Noble agar before imaging. Scale bar $100 \mu \mathrm{m}$ (b) Representative time-lapse images showing GBM8 preferentially invaded as single cells (white arrowheads) while GBM4 invaded in a collective manner as a group (white arrows). Images were taken $10 \mathrm{~min}$ apart at a $5 \mu \mathrm{m}$ step size using confocal microscopy. Scale bar $100 \mu \mathrm{m}$ (c) Mean velocity of GBM4 and GBM8 single cells in mouse wild-type spheroids. The data shown here are pooled from at least three experiments. Data were analyzed by Student's t test. ${ }^{*} P<0.05$.

a
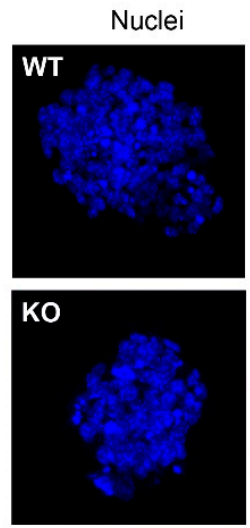

b

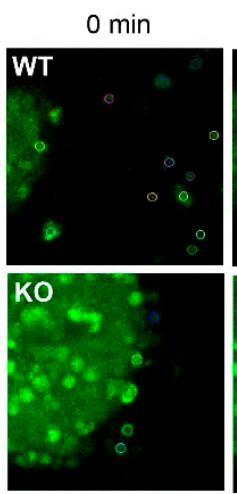

$\mathrm{Cx} 43$
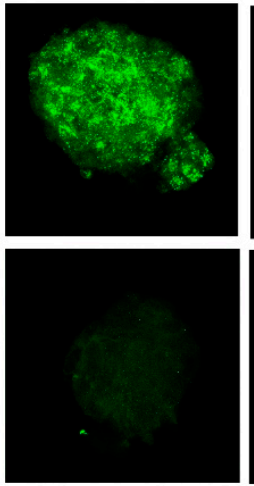

$40 \mathrm{~min}$
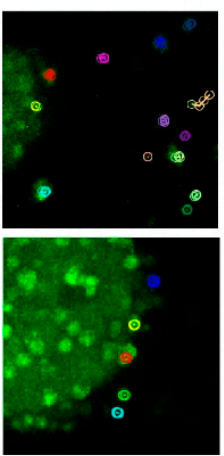

GFAP
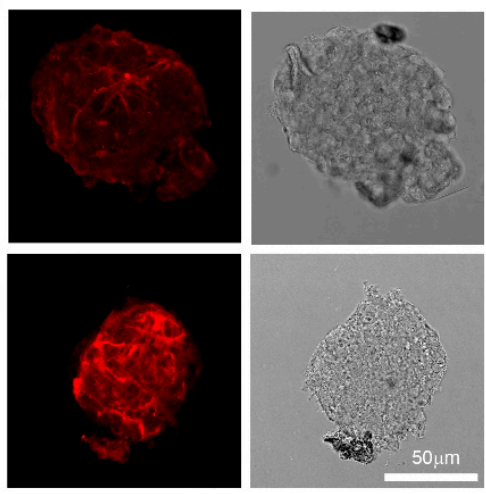

C

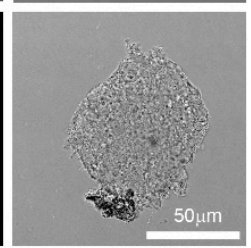

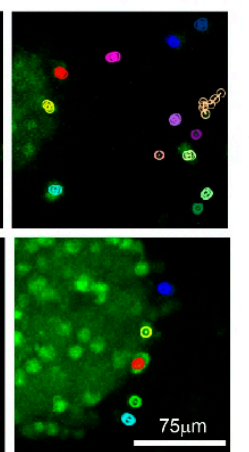

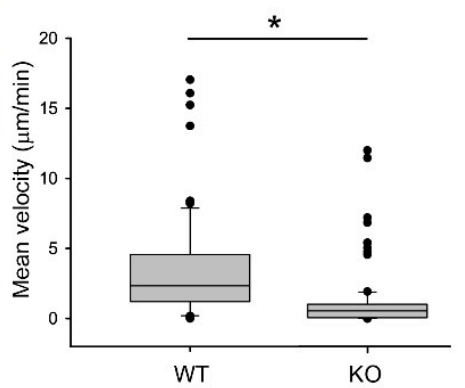

Figure 3. Elimination of $\mathrm{Cx} 43$ in mouse progenitor cells reduces GBM8 invasion. (a) Wild-type (WT) and Cx43 knockout (KO) spheroids were co-stained with anti-Cx43 and anti-GFAP antibodies. 
GFAP was detected in both WT and KO spheroids. In contrast, the punctate staining of Cx43 was only detected in WT but not the KO spheroids, confirming successful knockout of Cx43 in the mouse progenitors. Scale bar $50 \mu \mathrm{m}$ (b) 3D cell tracking was carried out using the Fiji plugin, MTrackJ. Representative images showing cell movement in two 40-min periods. The track of a single cell is denoted by a colored lane in a 3D projection. Each circle represents the $x, y, z$ location of the cell at a time point from 0 to $40 \mathrm{~min}$, and from 0 to $80 \mathrm{~min}$. The difference between 40 and $80 \mathrm{~min}$ track illustrates the movement of cells during this time interval. Note that the movement of a cell in the $\mathrm{z}$ direction will not be apparent in these 2D representative images. Scale bar $75 \mu \mathrm{m}$ (c) Mean velocity of GBM8 in WT and $\mathrm{KO}$ mouse spheroids. The data shown here are pooled from at least three experiments. Data were analyzed by Student's t test. ${ }^{*} P<0.05$.

\section{Discussion}

The tissue environment that envelops the glioma cells not only affects the dissemination of cancer cells, but it also influences the susceptibility of cancer cells to therapeutic intervention [24]. One prominent feature of the glioma microenvironment is the presence of a large number of reactive astrocytes exhibiting increased GFAP and Cx43 expression in the peri-tumor region [15,25-27]. In this environment, Cx43-mediated GJIC is expected to occur between glioma cells, between astrocytes and heterocellularly between glioma cells and astrocytes. In the latter case, $\mathrm{Cx} 43$ has been shown to be a facilitator in tumor invasion by allowing transfer or exchange of signaling molecules such as miRNA or cGAMP between cancer cells and astrocytes [16,28].

An early study indicates that $90 \%$ of recurrent gliomas occur within $2 \mathrm{~cm}$ of the resected tumor [29]. Therefore, we developed a 3D platform with the capacity to quickly quantify the invasion of patient-derived glioma cells into normal tissue, focusing on the invasive niche [30] at the tumor-stromal interface. In addition, a tumor organoid culture will have the advantage of having cellular complexities that better assess therapeutic response [31]. As a proof-of-principle study, we demonstrated that the absence of Cx43 in mouse progenitor cells is sufficient to affect human BTICs invasion in a 3D culture system.

Cx43-dependent signaling pathways in the tumor microenvironment are emerging to be attractive anti-cancer targets. Carbenoxolone, a widely used Cx43 gap junction inhibitor, enhanced glioma cell death and survival of treated mice by $27 \%$ [32]. Meclofenamate is a promising orally bioavailable therapeutic that inhibits gap junction-mediated processes [28] and is now being tested in human patients with recurrent or progressive brain metastasis (https://clinicaltrials.gov/ct2/show/NCT02429570). Recently, we reported that the application of a TAT-Cx $43_{266-283}$ peptide that mimics the effect of $\mathrm{Cx} 43$ on c-Src inhibition reduces the growth and invasion of human glioma stem cells in immunodeficient mice, without adversely affecting neurons and astrocytes [33]; similarly, the TAT-Cx43 peptide reduces the invasiveness of mouse glioma cells GL261 in an immunocompetent mouse model [33].

Increasing evidence suggests that somatic alterations of the genome in host tissue contribute to tumor invasion [34,35]. A co-culture of patient-derived glioma cells with normal cells from the same patient in a 3D system will better mimic glioma invasion in an intact brain. Therefore, having determined that the absence of Cx43 reduces glioma invasion in our 3D model, our next objective is to examine the efficacy of $\mathrm{C} \times 43$ inhibitors with normal spheroids generated from human-induced pluripotent stem cells. Instead of using confocal microscopy to track invasion, a high content array image scanner will greatly increase throughput by screening multiple drug combinations on glioma samples. Our platform will potentially have a wide application to assess the efficacy of cancer treatment with matching patient tumor and normal spheroids of different types of human cancers, thereby facilitating the translation to personalized oncology. 


\section{Materials and Methods}

\subsection{Generation of Cx43 Knockout Mouse Progenitor Cells}

Cx43 conditional knockout mice were generated by crossing mice containing GFAP-Cre [36] with C57BL mice harboring floxed Cx43 alleles [37]. Mice of either sex were used in the experiment, maintained in an animal facility for a $12 \mathrm{~h}$ light/dark cycle and were provided food and water ad libitum. All breeding and animal procedures were approved by The University of British Columbia Animal Care Committee (Protocol No: A09-0847) and performed in accordance with the guidelines established by the Canadian Council on Animal Care. Mouse neural progenitor stem cells were isolated from mice, similar to the procedure described in [38] and modified as described in [39]. Briefly, cortices freed of meninges were dissociated with $0.25 \%$ trypsin-EDTA at $37^{\circ} \mathrm{C}$ for $5 \mathrm{~min}$. The digested cortices were washed twice with DMEM supplemented with $10 \%$ FBS and gently triturated in DMEM without FBS with a p200 pipette tip. After pelleting, the cell suspension was resuspended in DMEM/F12 (Life Technologies, Carlsbad, CA, USA) and passed through a $40 \mu \mathrm{m}$ cell strainer (BD Biosciences, San Jose, CA, USA) and plated at $2 \times 10^{4} / \mathrm{cm}^{2}$ in complete NeuroCult media (STEMCELL Technologies, Vancouver, BC, Canada) supplemented with $20 \mathrm{ng} / \mathrm{mL}$ rhEGF (STEMCELL Technologies, Vancouver, BC, Canada), 10 ng FGF (STEMCELL Technologies, Vancouver, BC, Canada) and 0.0002\% Heparin (STEMCELL Technologies, Vancouver, BC, Canada). Human BTICs, GBM4 and GBM8 [20,40] were cultured in the same media. Spheroids were subcultured with Accutase (STEMCELL Technologies, Vancouver, BC, Canada) according to the manufacturer's instructions.

\subsection{Preparation of Spheroids for Imaging}

To generate spheroids for the invasion experiments, $10^{5}$ isolated cells were plated in a 6-well plate with gentle rotational shaking at approximately $34 \mathrm{rpm}$ and allowed to form spheroids for $2 \mathrm{~d}$ in the presence of either CellTracker CMTPX (Red dye, Invitrogen, Carlsbad, CA, USA), CMAC (Blue dye, Invitrogen, Carlsbad, CA, USA) or CMFDA (Green dye, Invitrogen, Carlsbad, CA, USA), respectively (Figure 1a). Combination was achieved by transferring labeled spheroids into a $2.0 \mathrm{~mL}$ Eppendorf tube using a sterile plastic eyedropper, washing once in PBS, then combining the spheroids of interest at the bottom of a $1.5 \mathrm{~mL}$ Eppendorf tube. The spheroids were allowed to settle at the bottom of an Eppendorf tube followed by a $1 \mathrm{~h}$ incubation at $37^{\circ} \mathrm{C}$ to allow contact adhesion to occur. For live cell imaging, aggregates were mounted in $0.8 \%$ Noble agar/PBS that had been cooled to $39^{\circ} \mathrm{C}$ prior to imaging in a $35 \mathrm{~mm}$ glass- bottom dish (MatTek Corporation, Ashland, MA, USA). A $37^{\circ} \mathrm{C}$ heater was used to warm the imaging chamber, beginning at least $3 \mathrm{~h}$ prior to the start of live cell imaging. Aggregated spheroids were imaged at single cell resolution with a Leica TCS SP5 II Basic VIS confocal system (Leica Microsystems, Wetzlar, Germany) at a time interval of 10 min for $2 \mathrm{~h}$.

\subsection{Analysis of Spheroids Invasion}

Images were analyzed, including color merging, maximal projections and 3D reconstructions using ImageJ (version 1.48v) software [41]. Individual BTICs migrating away from the spheroid into the C57BL mouse neurospheres were tracked using the MTrackJ plugin [42].

\subsection{Immunofluorescence of Self-Assembled Spheroids}

Mouse spheroids of less than $100 \mu \mathrm{m}$ in diameter were fixed with $4 \%$ paraformaldehyde in PBS for $30 \mathrm{~min}$ at room temperature with gentle inversion, followed by three washes of PBS. The spheroids were blocked for $1 \mathrm{~h}$ at room temperature in 2\% BSA and $0.3 \%$ Triton X-100, incubated overnight at $4{ }^{\circ} \mathrm{C}$ in $1 \%$ BSA and $0.1 \%$ Triton X-100 with rabbit anti-Cx43 (1:200, Sigma-Aldrich, St. Louis, MO, USA) and mouse anti-GFAP (1:100, Sigma-Aldrich, St. Louis, MO, USA), probed with Alexa Fluor-conjugated secondary antibodies (1:500, Invitrogen, Carlsbad, CA, USA), mounted in Prolong Antifade mounting media with 4'-6-diamidino-2-phenylindole (DAPI) (Invitrogen, Carlsbad, CA, USA) and visualized with a Leica TCS SP5 II Basic VIS confocal system. 


\subsection{Protein Isolation and Western Analysis}

GBM4 and GBM8 cell pellets were lysed in a buffer containing $0.1 \%$ SDS, $1 \%$ IGEPAL, $0.5 \%$ Sarkosyl, $50 \mathrm{mM}$ Tris- $\mathrm{HCl}(\mathrm{pH} 8.0), 150 \mathrm{mM} \mathrm{NaCl}$ supplemented with protease inhibitors (Roche Applied Science, Penzberg, Germany) and phosphatase inhibitors (Sigma-Aldrich, St. Louis, MO, USA). Rabbit anti-Cx43 (1:3000, Sigma-Aldrich, St. Louis, MO, USA) and anti-GAPDH (1:10,000, Hytest, Turku, Finland) were used as primary antibodies, followed by either anti-rabbit-HRP or anti-mouse-HRP (Sigma-Aldrich, St. Louis, MO, USA) as secondary antibodies. Protein bands were detected with Amersham ECL western detection reagents (GE Healthcare, Chicago, IL, USA).

\subsection{Statistical Analysis}

SigmaPlot version 13.0 software (San Jose, CA, USA) was used for statistical analysis. The results are presented as mean $+/$ SEM. Data were analyzed by Student's $t$ test. $P<0.05$ was considered significant.

Author Contributions: Conceptualization, W.C.S. and C.C.N.; Methodology, K.K. and W.C.S.; Data Analysis, K.K. and W.C.S.; Writing-Original Draft Preparation, K.K. and W.C.S.; Writing-Review \& Editing, W.C.S. and C.C.N.; Supervision, W.C.S.; Funding Acquisition, C.C.N. All authors have read and agreed to the published version of the manuscript.

Funding: This research was funded by Natural Sciences and Engineering Research Council of Canada (RGPIN-2016-05471) and two operating grants from the Canadian Institutes of Health Research (MOP-102489 and MOP-93572). CCN was supported by the Canada Research Chair Program.

Acknowledgments: We thank Karen Guo, Nicolas Theodoric, Jonathan Lelowski and Derek M. van Pel for providing technical support for this project.

Conflicts of Interest: The authors declare no conflicts of interest.

\section{References}

1. Gielen, P.R.; Aftab, Q.; Ma, N.; Chen, V.C.; Hong, X.; Lozinsky, S.; Naus, C.C.; Sin, W.C. Connexin43 confers Temozolomide resistance in human glioma cells by modulating the mitochondrial apoptosis pathway. Neuropharmacology 2013, 75, 539-548. [CrossRef]

2. Shaw, E.G.; Berkey, B.; Coons, S.W.; Bullard, D.; Brachman, D.; Buckner, J.C.; Stelzer, K.J.; Barger, G.R.; Brown, P.D.; Gilbert, M.R.; et al. Recurrence following neurosurgeon-determined gross-total resection of adult supratentorial low-grade glioma: Results of a prospective clinical trial. J. Neurosurg. 2008, 109, 835-841. [CrossRef] [PubMed]

3. Cottin, S.; Ghani, K.; De Campos-Lima, P.O.; Caruso, M. Gemcitabine intercellular diffusion mediated by gap junctions: New implications for cancer therapy. Mol. Cancer 2010, 9, 141. [CrossRef] [PubMed]

4. Naus, C.C.; Laird, D.W. Implications and challenges of connexin connections to cancer. Nat. Rev. Cancer 2010, 10, 435-441. [CrossRef] [PubMed]

5. Mesnil, M.; Crespin, S.; Avanzo, J.L.; Zaidan-Dagli, M.L. Defective gap junctional intercellular communication in the carcinogenic process. Biochim. Biophys. Acta 2005, 1719, 125-145. [CrossRef] [PubMed]

6. Aasen, T.; Mesnil, M.; Naus, C.C.; Lampe, P.D.; Laird, D.W. Gap Junctions and Cancer: Communicating for 50 Years. Nat. Rev. Cancer 2016, 16, 775-788. [CrossRef]

7. Sin, W.C.; Crespin, S.; Mesnil, M. Opposing roles of connexin43 in glioma progression. Biochim. Biophys. Acta 2012, 1818, 2058-2067. [CrossRef]

8. Strale, P.O.; Clarhaut, J.; Lamiche, C.; Cronier, L.; Mesnil, M.; Defamie, N. Down-regulation of connexin43 expression reveals the involvement of caveolin-1 containing lipid rafts in human U251 glioblastoma cell invasion. Mol. Carcinog. 2012, 51, 845-860. [CrossRef]

9. Oliveira, R.; Christov, C.; Guillamo, J.S.; De Bouard, S.; Palfi, S.; Venance, L.; Tardy, M.; Peschanski, M. Contribution of gap junctional communication between tumor cells and astroglia to the invasion of the brain parenchyma by human glioblastomas. BMC Cell Biol. 2005, 6, 7. [CrossRef]

10. Lin, J.H.; Takano, T.; Cotrina, M.L.; Arcuino, G.; Kang, J.; Liu, S.; Gao, Q.; Jiang, L.; Li, F.; Lichtenberg-Frate, H.; et al. Connexin 43 enhances the adhesivity and mediates the invasion of malignant glioma cells. J. Neurosci. 2002, 22, 4302-4311. [CrossRef] 
11. Zhang, W.; Couldwell, W.T.; Simard, M.F.; Song, H.; Lin, J.H.; Nedergaard, M. Direct gap junction communication between malignant glioma cells and astrocytes. Cancer Res. 1999, 59, 1994-2003. [PubMed]

12. Uzu, M.; Sin, W.C.; Shimizu, A.; Sato, H. Conflicting Roles of Connexin43 in Tumor Invasion and Growth in the Central Nervous System. Int. J. Mol. Sci. 2018, 19, 1159. [CrossRef]

13. Grek, C.L.; Sheng, Z.; Naus, C.C.; Sin, W.C.; Gourdie, R.G.; Ghatnekar, G.G. Novel approach to temozolomide resistance in malignant glioma: Connexin43-directed therapeutics. Curr. Opin. Pharmacol. 2018, 41, 79-88. [CrossRef] [PubMed]

14. Nevo, I.; Woolard, K.; Cam, M.; Li, A.; Webster, J.D.; Kotliarov, Y.; Kim, H.S.; Ahn, S.; Walling, J.; Kotliarova, S.; et al. Identification of molecular pathways facilitating glioma cell invasion in situ. PLoS ONE 2014, 9, e111783. [CrossRef] [PubMed]

15. Sin, W.C.; Aftab, Q.; Bechberger, J.F.; Leung, J.H.; Chen, H.; Naus, C.C. Astrocytes promote glioma invasion via the gap junction protein connexin43. Oncogene 2016, 35, 1504-1516. [CrossRef]

16. Hong, X.; Sin, W.C.; Harris, A.L.; Naus, C.C. Gap junctions modulate glioma invasion by direct transfer of microRNA. Oncotarget 2015, 6, 15566-15577. [CrossRef]

17. Van Pel, D.M.; Harada, K.; Song, D.; Naus, C.C.; Sin, W.C. Modelling glioma invasion using 3D bioprinting and scaffold-free 3D culture. J. Cell Commun. Signal. 2018, 12, 723-730. [CrossRef]

18. Gimple, R.C.; Bhargava, S.; Dixit, D.; Rich, J.N. Glioblastoma stem cells: Lessons from the tumor hierarchy in a lethal cancer. Genes Dev. 2019, 33, 591-609. [CrossRef]

19. Ortensi, B.; Setti, M.; Osti, D.; Pelicci, G. Cancer stem cell contribution to glioblastoma invasiveness. Stem Cell Res. Ther. 2013, 4, 18. [CrossRef]

20. Wakimoto, H.; Kesari, S.; Farrell, C.J.; Curry, W.T., Jr.; Zaupa, C.; Aghi, M.; Kuroda, T.; Stemmer-Rachamimov, A.; Shah, K.; Liu, T.C.; et al. Human glioblastoma-derived cancer stem cells: Establishment of invasive glioma models and treatment with oncolytic herpes simplex virus vectors. Cancer Res. 2009, 69, 3472-3481. [CrossRef]

21. Musil, L.S.; Cunningham, B.A.; Edelman, G.M.; Goodenough, D.A. Differential phosphorylation of the gap junction protein connexin43 in junctional communication-competent and -deficient cell lines. J. Cell Biol. 1990, 111, 2077-2088. [CrossRef] [PubMed]

22. Musil, L.S.; Goodenough, D.A. Biochemical analysis of connexin 43 intracellular transport, phosphorylation, and assembly into gap junctional plaques. J. Cell Biol. 1991, 115, 1357-1374. [CrossRef] [PubMed]

23. Theodoric, N.; Bechberger, J.F.; Naus, C.C.; Sin, W.C. Role of gap junction protein Connexin43 in astrogliosis induced by brain injury. PLoS ONE 2012, 7, e47311. [CrossRef]

24. McMillin, D.W.; Negri, J.M.; Mitsiades, C.S. The role of tumour-stromal interactions in modifying drug response: Challenges and opportunities. Nat. Rev. Drug Discov. 2013, 12, 217-228. [CrossRef]

25. Colombo, E.; Farina, C. Astrocytes: Key Regulators of Neuroinflammation. Trends Immunol. 2016, 37, 608-620. [CrossRef] [PubMed]

26. Lee, J.; Borboa, A.K.; Baird, A.; Eliceiri, B.P. Non-invasive quantification of brain tumor-induced astrogliosis. BMC Neurosci. 2011, 12, 9. [CrossRef] [PubMed]

27. Baklaushev, V.P.; Yusubalieva, G.M.; Tsitrin, E.B.; Gurina, O.I.; Grinenko, N.P.; Victorov, I.V.; Chekhonin, V.P. Visualization of Connexin 43-positive cells of glioma and the periglioma zone by means of intravenously injected monoclonal antibodies. Drug Deliv. 2011, 18, 331-337. [CrossRef]

28. Chen, Q.; Boire, A.; Jin, X.; Valiente, M.; Er, E.E.; Lopez-Soto, A.; Jacob, L.S.; Patwa, R.; Shah, H.; Xu, K.; et al. Carcinoma-astrocyte gap junctions promote brain metastasis by cGAMP transfer. Nature 2016, 533, 493-498. [CrossRef]

29. Hochberg, F.H.; Pruitt, A. Assumptions in the radiotherapy of glioblastoma. Neurology 1980, 30, 907-911. [CrossRef]

30. Lathia, J.D.; Heddleston, J.M.; Venere, M.; Rich, J.N. Deadly teamwork: Neural cancer stem cells and the tumor microenvironment. Cell Stem Cell 2011, 8, 482-485. [CrossRef]

31. Pauli, C.; Hopkins, B.D.; Prandi, D.; Shaw, R.; Fedrizzi, T.; Sboner, A.; Sailer, V.; Augello, M.; Puca, L.; Rosati, R.; et al. Personalized In Vitro and In Vivo Cancer Models to Guide Precision Medicine. Cancer Discov. 2017, 7, 462-477. [CrossRef] [PubMed]

32. Yulyana, Y.; Endaya, B.B.; Ng, W.H.; Guo, C.M.; Hui, K.M.; Lam, P.Y.; Ho, I.A. Carbenoxolone enhances TRAIL-induced apoptosis through the upregulation of death receptor 5 and inhibition of gap junction intercellular communication in human glioma. Stem Cells Dev. 2013, 22, 1870-1882. [CrossRef] [PubMed] 
33. Jaraiz-Rodriguez, M.; Talaveron, R.; Garcia-Vicente, L.; Pelaz, S.G.; Dominguez-Prieto, M.; Alvarez-Vazquez, A.; Flores-Hernandez, R.; Sin, W.C.; Bechberger, J.; Medina, J.M.; et al. Connexin43 peptide, TAT-Cx43266-283, selectively targets glioma cells, impairs malignant growth, and enhances survival in mouse models in vivo. Neuro Oncol. 2020, 22, 493-504. [CrossRef] [PubMed]

34. Carter, H.; Marty, R.; Hofree, M.; Gross, A.M.; Jensen, J.; Fisch, K.M.; Wu, X.; DeBoever, C.; Van Nostrand, E.L.; Song, Y.; et al. Interaction Landscape of Inherited Polymorphisms with Somatic Events in Cancer. Cancer Discov. 2017, 7, 410-423. [CrossRef] [PubMed]

35. Eng, C.; Leone, G.; Orloff, M.S.; Ostrowski, M.C. Genomic alterations in tumor stroma. Cancer Res. 2009, 69, 6759-6764. [CrossRef] [PubMed]

36. Casper, K.B.; McCarthy, K.D. GFAP-positive progenitor cells produce neurons and oligodendrocytes throughout the CNS. Mol. Cell Neurosci. 2006, 31, 676-684. [CrossRef]

37. Theis, M.; Mas, C.; Doring, B.; Kruger, O.; Herrera, P.; Meda, P.; Willecke, K. General and conditional replacement of connexin43-coding DNA by a lacZ reporter gene for cell-autonomous analysis of expression. Cell Commun. Adhes. 2001, 8, 383-386. [CrossRef]

38. Sin, W.C.; Moniz, D.M.; Ozog, M.A.; Tyler, J.E.; Numata, M.; Church, J. Regulation of early neurite morphogenesis by the $\mathrm{Na}+\mathrm{H}+$ exchanger NHE1. J. Neurosci. 2009, 29, 8946-8959. [CrossRef]

39. Ahlenius, H.; Kokaia, Z. Isolation and generation of neurosphere cultures from embryonic and adult mouse brain. Methods Mol. Biol. 2010, 633, 241-252.

40. Wakimoto, H.; Mohapatra, G.; Kanai, R.; Curry, W.T., Jr.; Yip, S.; Nitta, M.; Patel, A.P.; Barnard, Z.R.; Stemmer-Rachamimov, A.O.; Louis, D.N.; et al. Maintenance of primary tumor phenotype and genotype in glioblastoma stem cells. Neuro Oncol. 2012, 14, 132-144. [CrossRef] [PubMed]

41. Schneider, C.A.; Rasband, W.S.; Eliceiri, K.W. NIH Image to ImageJ: 25 years of image analysis. Nat. Methods 2012, 9, 671-675. [CrossRef] [PubMed]

42. Meijering, E.; Dzyubachyk, O.; Smal, I. Methods for cell and particle tracking. Methods Enzymol. 2012, 504, 183-200. [PubMed]

(C) 2020 by the authors. Licensee MDPI, Basel, Switzerland. This article is an open access article distributed under the terms and conditions of the Creative Commons Attribution (CC BY) license (http://creativecommons.org/licenses/by/4.0/). 